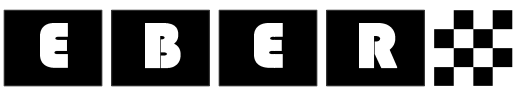

Entrepreneurial Business and Economics Review

2013, Vol. 1, No. 2

\title{
Editorial: Modern Challenges for International Business in Europe
}

Globalisation, integration, regionalisation or integration processes are indeed very crucial for local businesses, which more and more often think globally and act locally (Kefalas, 1998), especially in Europe, thus globalisation and Europeanisation processes are currently key contemporary challenges for international businesses in Europe.

This issue of 'Entrepreneurial Business and Economics Review' (EBER) exemplifies that our new journal is truly multi-disciplinary and multi-contextual as declared by Krzysztof Wach (2013), Editor-in-chief in his Editorial for an opening issue of EBER. Consequently, there is an intrinsic difficulty in identification of a common denominator for all of the articles published in this issue. Despite the leading topic of this issue which are challenges for international business in Europe, a reader may quickly recognize that problems presented and analysed here cross scientific disciplines (economics, management) and geographic (Europe) borders. One may perceive this as a deficiency but other readers may consider this multidimensionality as an inherent component of our times we should accept and - if possible - embrace for good. There is, however, one element which can be seen as a common feature for nearly all of the articles in this issue. Namely they were written by young researchers and scholars from Spain, Serbia and Poland. This gives us a unique opportunity to see what young scholars identify as modern challenges worthy of further exploration. Among these challenges one may find foreign investments (various aspects of are present in four articles), entrepreneurial orientation of firms, firms' strategies and policies and the broad concept of internationalization of firms.

Four out of six papers published in this issue are literature reviews, while two articles are research papers.

Agnieszka Żur (an assistant professor at the Cracow University of Economics, Poland) in her article Entrepreneurial Orientation and Firm Performance - Challenges for Research and Practice presents a critical review of the literature identifying performance parameters affecting entrepreneurial firms. The article outlines which of these parameters have been empirically tested and which require further attention.

Milica Latinovic and Tijana Obradovic (who are assistant lecturers at the University of Belgrade, Serbia) in The Performance of Socially Responsible Investments are attempting to capture the link between corporate social responsibility and shareholder value from the point of view of socially responsible investments.

Elena Pawęta (a PhD student at the University of Lodz, Poland) in her article entitled The Determinants of Born Global Companies Emergence in Central European Countries is 
tracing factors fostering early internationalization of firms from the Czech Republic, Hungary, Poland and Slovakia.

Sara Jiménez Burillo (a PhD student at the University of Castilla-La Mancha, Spain) and Juan J. Jiménez Moreno (a full professor at the University of Castilla-La Mancha, Spain) in their article The Role of the Top Management Team in the Choice of Entry Modes - Theoretical Perspective decided to study how top management teams are addressing the issue of appropriate (and effective) internationalisation strategies of their firms and how these problems are presented in the literature.

Artur K. Modliński (a PhD student at the University of Lodz, Poland) in his article entitled Transitive Business Model of Management in Central Europe - Torn between East and West presents key findings from research on organization cultures (using Geert Hofstede's methodology) in Germany, Poland and the Ukraine.

The article Government Incentives and FDI inflow into R\&D. The Case of Countries written by Magdalena Owczarczuk (an assistant lecturer at the University of Białystok, Poland) is aimed at identifying and comparing various incentives and measures used by the governments in the Czech Republic, Hungary, Poland and Slovakia to attract foreign investments in various research and development projects.

All the articles in this issue will not leave readers neutral. Some of the judgements presented below may be perceived as not adequately supported by the findings from the research or - for any other reasons - controversial. Because such possible controversies may lead to scientific dispute which is a basic nourishment for scientists and researchers, one may only welcome such a scenario.

I would like to take this opportunity and to extend my thanks to Krzysztof Wach and my Colleagues (not mentioned by names) who dedicated a lot of their time and made this issue of EBER possible.

Jacek Klich

Issue Editor

\section{REFERENCES}

Kefalas, A.G., (1998). Think globally, act locally, Thunderbird International Business Review, 40(6), pp. 547-562.

Wach, K., (2013). Editorial: Global Opportunities and Local Businesses, Entrepreneurial Business and Economics Review, 1(1), pp. 5-6. 